\title{
Online elemental analysis of process gases with ICP-OES: A case study on waste wood combustion
}

\author{
Marco Wellinger ${ }^{\mathrm{a}, \mathrm{b}, *}$, Joerg Wochele ${ }^{\mathrm{a}}$, Serge M.A. Biollaz ${ }^{\mathrm{a}}$, Christian Ludwig ${ }^{\mathrm{a}, \mathrm{b}, *}$ \\ ${ }^{a}$ General Energy Research Department, Paul Scherrer Institute, CH-5232 Villigen PSI, Switzerland \\ ${ }^{\mathrm{b}}$ École Polytechnique Fédérale de Lausanne (EPFL), School of Architecture, Civil and Environmental Engineering (ENAC-IIE), CH-1015 Lausanne, Switzerland
}

\section{A R T I C L E I N F O}

\section{Article history:}

Received 21 November 2011

Accepted 10 May 2012

Available online 26 June 2012

\section{Keywords:}

Waste wood

Trace elements

ICP-OES

Online analysis

\begin{abstract}
A B S T R A C T
A mobile sampling and measurement system for the analysis of gaseous and liquid samples in the field was developed. An inductively coupled plasma optical emission spectrometer (ICP-OES), which is built into a van, was used as detector. The analytical system was calibrated with liquid and/or gaseous standards. It was shown that identical mass flows of either gaseous or liquid standards resulted in identical ICP-OES signal intensities. In a field measurement campaign trace and minor elements in the raw flue gas of a waste wood combustor were monitored. Sampling was performed with a highly transport efficient liquid quench system, which allowed to observe temporal variations in the elemental process gas composition. After a change in feedstock an immediate change of the element concentrations in the flue gas was detected. A comparison of the average element concentrations during the combustion of the two feedstocks showed a high reproducibility for matrix elements that are expected to be present in similar concentrations. On the other hand elements that showed strong differences in their concentration in the feedstock were also represented by a higher concentration in the flue gas. Following the temporal variations of different elements revealed strong correlations between a number of elements, such as chlorine with sodium, potassium and zinc, as well as arsenic with lead, and calcium with strontium.
\end{abstract}

() 2012 Elsevier Ltd. All rights reserved.

\section{Introduction}

Waste wood has a large potential for energy and heat production as biomass or waste. As customer demand for electricity and heat production continues to grow, reliance on renewable resources like waste streams are coming under increased regulatory scrutiny. When using waste or biomass feedstocks in thermal processes, trace elements present in these feedstocks may hinder the processes themselves, as well as pose a threat to equipment or the environment. Moreover, the content of these trace elements varies strongly even within a single feedstock type (Monkhouse, 2002; Williams, 2005; Demirbas, 2005; Krook et al., 2004). Due to the often strongly heterogeneous composition of waste streams combined with high dynamics of thermal reactions, the elemental concentrations in the process gas are reported to show a high temporal variability (Poole et al., 2007; Morf et al., 2000). Also, the absolute range of concentrations for different elements can vary from less than $1 \mu \mathrm{g} / \mathrm{m}_{\mathrm{N}}^{3}$ to more than $100 \mathrm{mg} / \mathrm{m}_{\mathrm{N}}^{3}$. Therefore a high linear calibration range and high temporal resolution of the detec-

\footnotetext{
* Corresponding authors. Address: General Energy Research Department, Paul Scherrer Institute, CH-5232 Villigen PSI, Switzerland. Tel.: +41 5631026 96; fax: +41563102624.

E-mail addresses: marco.wellinger@gmail.com (M. Wellinger), christian.ludwig@psi.ch (C. Ludwig).
}

tion method are essential to conduct a meaningful measurement of elemental composition of process gas streams. For a comprehensive review of different online detection methods of metal species in industrial processes see Monkhouse (2011). Additional challenges for the measurement equipment are high loads of tars and particles that are present in the gas stream of some thermal processes. For example in gasification tar and fine particles $(<1 \mu \mathrm{m})$ can reach loads of $150 \mathrm{~g} / \mathrm{m}_{\mathrm{N}}^{3}$ and $100 \mathrm{~g} / \mathrm{m}_{\mathrm{N}}^{3}$, respectively (Nagel, 2008). In order to conduct a measurement of actual explanatory power it is essential to sample producer gases in a way that combines a representative measurement technique with high resilience to tars and particles and a high time resolution. An additional challenge when conducting measurements in the field is the distance between the sampling port and the analytical instrument. Often the instrument's nearest possible placement is several dozen meters away from the sampling port. Long sampling lines can cause loss of analyte signal through unspecific adsorption as well as element specific reactions leading to depletion in the sample mass stream. When conducting direct gas measurements with process gases containing high loads of water and tars, for example in gasifier product gases, it can lead to a strong signal loss and can even cause blockage of the sampling line. To avoid condensation, the sampling lines have to be heated to a temperature level lying above the dew point of the compound in question. 
In this paper we present method development on ICP-OES measurements of process gases using both direct gas measurements and an indirect measurement using a liquid quench system. Our own measurements revealed that high transport losses occur when conducting direct gas measurements, even when working with a gas quench and heated sampling lines, though previous work has shown that when using high flow velocities (over $8 \mathrm{~m} / \mathrm{s}$ ) these problems can be overcome to some extent, even with a sampling line length of $40 \mathrm{~m}$ (Clarkson et al., 2003). However, the transport of sample gas into the detection unit remains challenging. In contrast to the direct gas measurements the liquid quench sampling revealed a high transport efficiency that enabled us to measure trace elemental concentrations down to two-digit ppb levels for a sampling line of $32 \mathrm{~m}$. In contrast to direct gas measurements the introduction of the liquid sample into the ICP-OES is a standard method. In a field measurement campaign the concentration of 23 elements were continuously measured in the raw flue gas of a waste wood combustion facility.

\section{Material and methods}

\subsection{ICP-OES}

The spectrometer (Spectro Ciros Vision SOP) used in our analyses is built into a van so it can be transported to field sites. An argon plasma at over $5000 \mathrm{~K}$ is used to atomize particles and molecules, and to further excite and ionize the atoms. The excited atoms and ions then emit photons at multiple wavelengths each of which is characteristic for a particular element. The emitted photons are then detected simultaneously by a series of charged coupled devices that range from ultraviolet to infrared $(125-770 \mathrm{~nm})$. With such an instrument it is possible to measure all elements besides argon, though practical limitations usually exclude measurements of hydrogen, fluorine, and noble gases.

ICP-OES instruments are designed to analyze aqueous samples in batch mode. To allow for a continuous online analysis the instrument had to be adapted in several regards. Firstly, we developed a new torch (sample introduction and support for the plasma flame) which allows a direct analysis of gaseous samples. Secondly, the analysis software had to be modified to allow for continuous measurement of more than 30 elements in an automated procedure. During the analysis of product gases from gasifiers, a carbon containing structure started to form within the base of the plasma, which degraded the plasma stability and signal intensities. Most likely this phenomena was related to the elevated content of tars in the gasifier product gas, as such phenomena did arise during the sampling of product gas from the wood combustor. After adding an additional stream of pure oxygen to the gas coming from the nebulizer the operation remained stable over several hours (Judex, 2010).

During the field measurements the ICP-OES has been operated using parameter settings shown in Table 1 .

For the field measurements we used an ultrasonic nebulizer (USN) by Cetac (U5000AT+). The USN is fed with liquid by a peristaltic pump (0.001 l/min liquid) and an argon gas stream $\left(0.8 \mathrm{l}_{\mathrm{N}} /\right.$ $\mathrm{min}$ ) as carrier gas. The nebulizer has an evaporation and a condensation loop to reduce the water content of the sample gas. The temperatures of evaporation loop and condensation loop were $120^{\circ} \mathrm{C}$ and $2{ }^{\circ} \mathrm{C}$, respectively. In contrast to pneumatic nebulizers that have efficiencies of $1-4 \%$, the USN has an efficiency of $10-15 \%$. The nebulizing efficiency is measured as mass flow output of analyte per mass flow input of the analyte. For the parameter settings of the USN used in this study an efficiency of $10 \%$ has been determined (Wellinger et al., 2011). The analysis of peaks using a back-
Table 1

Main ICP-OES operating conditions.

\begin{tabular}{ll}
\hline Parameter & Value \\
\hline Generator frequency $(\mathrm{MHz})$ & 27.12 \\
Power $\mathrm{RF}(\mathrm{kW})$ & 1700 \\
Plasma gas flow rate $\left(1 \mathrm{~min}^{-1}\right)$ & 14.5 \\
Auxiliary gas flow rate $\left(\mathrm{min}^{-1}\right)$ & 0.7 \\
Aerosol carrier gas flow rate $\left(1 \mathrm{~min}^{-1}\right)$ & 0.8 \\
Liquid sample flow rate $\left(\mathrm{ml} \mathrm{min}{ }^{-1}\right)$ & 1 \\
Injector tube diameter $(\mathrm{mm})$ & 8 \\
Nebulizer heater temperature $\left({ }^{\circ} \mathrm{C}\right)$ & 120 \\
Nebulizer condenser temperature $\left({ }^{\circ} \mathrm{C}\right)$ & -2 \\
\hline
\end{tabular}

ground correction that automatically corrects for changes in the level of background noise (Poole et al., 2005).

\subsection{Gas quench measurements}

The gas quench method being used in this work is similar to a condensation interface used in previous studies (Kowalski et al., 2011; Ludwig et al., 2001, 2007). Its general working principle is characterized by generating particles in the submicron range (Kowalski et al., 2011). The gaseous particles that enter the condensation interface are limited in their growth by rapid quench with cold argon gas in excess, which generates aerosols suitable to transportation through sampling lines. For a more detailed description of the gas quench system see Wellinger et al., 2011.

\subsubsection{Analyte sensitivity of liquid versus gaseous standards}

The ICP-OES is commonly used to analyze samples in aqueous solutions. Standard calibration procedure of the ICP-OES system is done with liquid reference solutions. Though for the purpose of characterizing process gases our instrument was modified to accept gaseous samples as well. Performing a direct gas calibration can be done, though in practice it is limited since only very few of the elements of interest (metals and semimetals) are commercially available as volatile (or gaseous) compounds (Timmermans et al., 2003). In the case of metals there are a few compounds available but they are either very toxic or highly explosive (e.g. $\mathrm{Zn}\left(\mathrm{CH}_{3}\right)_{2}, \mathrm{Hg}\left(\mathrm{CH}_{3}\right)_{2}$, and $\left.\mathrm{C}_{8} \mathrm{H}_{20} \mathrm{~Pb}\right)$, which makes them unsuitable for the use as standards. To overcome this limitation, we investigated the equivalency of a calibration with nebulized aqueous solutions as compared to direct injections of gaseous standards. We used commercially available sulfur compounds of carbonyl sulfide (COS), hydrogen sulfide $\left(\mathrm{H}_{2} \mathrm{~S}\right)$ and thiophene $\left(\mathrm{C}_{4} \mathrm{H}_{4} \mathrm{~S}\right)$ as traces in a matrix of argon gas. To vary the concentrations of the gaseous sulfur compounds we used mass flow controllers to inject differing mixtures of gas standard and argon to a flow totaling $0.15 \mathrm{l}_{\mathrm{N}} / \mathrm{min}$. The use of a standard mass flow controller limits the maximum concentration range to a factor of 20 for each gas mixture. We then measured the signal intensities generated by direct injection of gas with the intensities by injection of aerosols from the nebulizer. We tested our hypothesis by checking to see if an equal mass flow from either gaseous compounds or nebulizer aerosols also generates equal signal intensities in the ICP-OES. For the measurements shown in Fig. 1 a crossflow nebulizer (Cetac, Scott type) was used. The nebulizer was being fed with $0.002 \mathrm{l} / \mathrm{min}$ liquid sample and $0.8 \mathrm{l}_{\mathrm{N}} / \mathrm{min}$ argon. The total argon flow through the torch was kept constant between gas and liquid measurements at $16 \mathrm{l}_{\mathrm{N}} / \mathrm{min}$. For the parameter settings used in this experiment the efficiency of the crossflow nebulizer is $1.5 \%$. The calculation of the mass flow was conducted according to the following equations:

For liquids : $d m / d t=d v / d t_{\text {pump }} * \eta * c_{\text {liq }}$

For gases : $d m / d t=d v / d t_{s t d} * c_{g a s}$ 


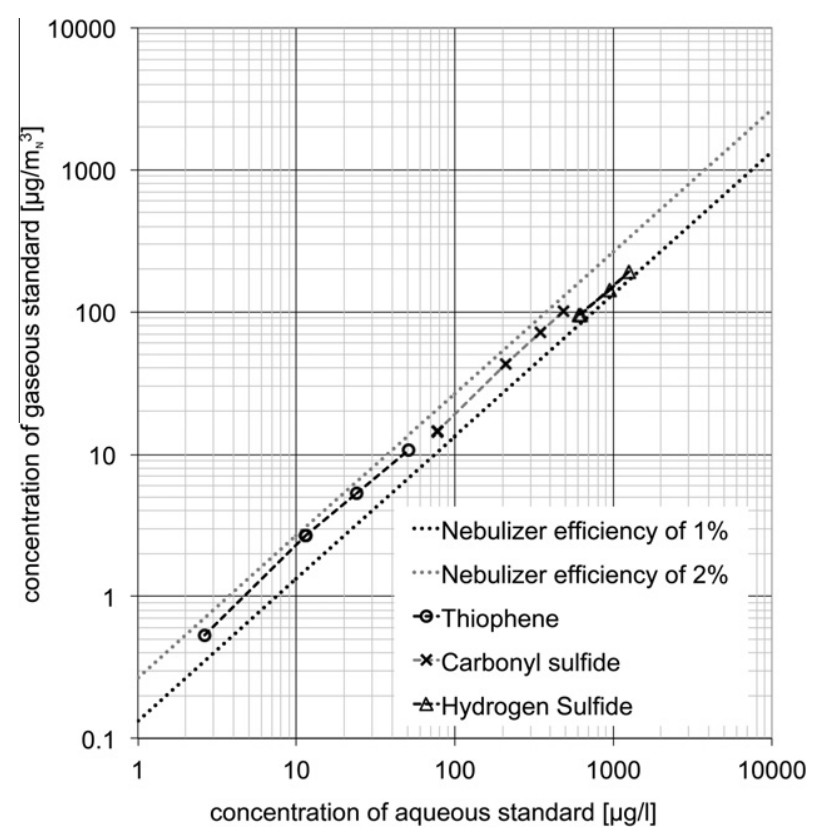

Fig. 1. Comparison of the ICP-OES signal sensitivity for gaseous versus aqueous standards.

$d m / d t$ is the mass flow of analyte $[\mu \mathrm{g} / \mathrm{min}], d v / d t_{\text {pump }}$ the liquid flow of the nebulizer feed pump [1/min], $\eta$ the efficiency of the nebulizer [1], $c_{\text {liq }}$ the concentration of the liquid standards $[\mu \mathrm{g} / \mathrm{l}], d v / d t_{\text {std }}$ the gas flow of the standard $\left[\mathrm{m}_{\mathrm{N}}^{3} / \mathrm{min}\right]$, and $c_{\text {gas }}$ is the concentration of the gaseous standards $\left[\mu \mathrm{g} / \mathrm{m}_{\mathrm{N}}^{3}\right]$.

Fig. 1 summarizes the results of these tests that were conducted with the following sulfur compounds: thiophene $\left(\mathrm{C}_{4} \mathrm{H}_{4} \mathrm{~S}\right)$, carbonyl sulfide (COS) and hydrogen sulfide $\left(\mathrm{H}_{2} \mathrm{~S}\right)$. The free linear correlations of the concentration of the gaseous standards $\left(c_{g a s}\right)$ and concentration of the liquid standards $\left(c_{\text {liq }}\right)$ the following correlation coefficients and standard errors $\left(s e_{y}\right)$ :

Thiophene : $R^{2}=0.9982 \quad s e_{y}= \pm 0.19\left[\mu \mathrm{g} / \mathrm{m}_{\mathrm{N}}^{3}\right]$

Carbonyl sulfide : $R^{2}=0.9998 s e_{y}= \pm 0.65\left[\mu \mathrm{g} / \mathrm{m}_{\mathrm{N}}^{3}\right]$

Hydrogen sulfide : $R^{2}=0.9983 s e_{y}= \pm 2.28\left[\mu \mathrm{g} / \mathrm{m}_{\mathrm{N}}^{3}\right]$

The measurements show a constant proportionality of the analyte input by gaseous standards to the analyte input by liquid standards using a concentric nebulizer for a fixed setting of the instrument parameters. The proportionality factor in our experiments matched the concentric nebulizer's efficiency (1.5\%). In Fig. 1 two auxiliary lines are drawn that represent the theoretical correlation between the concentrations of an aqueous standard to that of a gaseous standard to reach the same mass flow to the ICP-OES for nebulizer efficiencies of $1 \%$ and $2 \%$, respectively.

\subsubsection{Influence of sampling line length when applying direct gas measurements}

To assess the transport efficiency of aerosols through a heated sampling line, we conducted tests with an ultrasonic nebulizer with direct sampling plus additional sampling lines with $3 \mathrm{~m}$ and $32 \mathrm{~m}$ length, respectively. In the presence of water we observed a strong decrease in signal intensity for tube lengths over a few meters even when using a sampling line heated to $120^{\circ} \mathrm{C}$.

The signals of twenty elements typically found in producer gases from thermal conversion of biomass were assessed relative to the initial signal intensities. At three meters all of the elements gave a decrease in signal of $10-30 \%$, except for chlorine, sulfur and lead. At $32 \mathrm{~m}$ the loss in signal intensity was between $95 \%$ to almost $100 \%$ relative to the signal when measuring directly $(1 \mathrm{~m})$. The distribution of the relative signals intensities at $32 \mathrm{~m}$ followed that of a normal distribution although the low numeric resolution used led to the formation of distinct steps. The Shapiro-Wilk test gave a test statistic of 0.9211 with a $p$-value of 0.1042 , which suggests that a significant portion of the variation stems from normally distributed random noise. After these initial tests with a direct gas measurement we concentrated on the implementation of the liquid quench method.

\subsection{Liquid quench measurements}

In Fig. 2 a schematic of the sampling setup for liquid quench measurements with the ICP-OES is illustrated. The raw gas was mixed thoroughly with water containing organic solvent and transported in a two-phase flow to the ICP-OES van. 1-methoxy2-propanol $\left(\mathrm{C}_{4} \mathrm{H}_{10} \mathrm{O}_{2}\right.$, CAS-No. 107-98-2) is used as solvent because of its much higher capability to solubilize tars in comparison to pure water. This ability to solubilize tars is particularly important when analyzing gasifier product gases that contain high tar loads. Because pure 1-methoxy-2-propanol yields a low nebulizing efficiency, it was used as a mixture containing $10 \%$ deionized water (Judex, 2010). Additionally, $0.05 \mathrm{~mol} / \mathrm{l} \mathrm{HNO}_{3}$ was also added to minimize precipitation. The volume flow of the gas is 500 -fold higher than the corresponding solvent flow. Inside the van it enters a cooling system where the majority of all soluble compounds are transferred into the solvent. Then the liquid-gas mixture enters a first phase separator. At the bottom of the separator the outgoing flow is set to a higher flow than the actual liquid flow that is being fed at the sampling lance. This is to prevent an overflow of the separator with liquid. To get rid of the residual gas the sampling mixture is fed to another phase separator before being transported to the ultrasonic nebulizer, which produces aerosols that are transported to the ICP torch. The time lag for this method depends on the length of the sampling line, which is determined by the nearest placement of the mobile spectrometer to the sampling location (see also Section 2.3.1). A similar sampling technique has been documented elsewhere (Kowalski et al., 2011; Wellinger et al., 2011). For the field measurements the calibration has been conducted with standards based on the same water-solvent mixture as used for the laboratory measurements.

\subsubsection{Response behavior of the liquid sampling system}

To determine the step response time as well as the fading curve of the liquid sampling system connected to the ICP-OES, a solution containing $100 \mathrm{mg} / \mathrm{l} \mathrm{Ca}\left(\mathrm{NO}_{3}\right)_{2}$ was injected at the sampling lance and then transported through a $32 \mathrm{~m}$ long sampling line. The analyte was transported in a two-phase mixture of air and a solvent mixture identical to that used during field measurements.

The influence of the length of the sampling line was tested by transporting aerosols from the USN through PTFE sampling lines, heated to $120^{\circ} \mathrm{C}$. The tested sampling line lengths were $1 \mathrm{~m}, 3 \mathrm{~m}$ and $32 \mathrm{~m}$.

To characterize the liquid quench sampling system we conducted a response test with a $32 \mathrm{~m}$ long sampling line. To determine the step response time as well as the fading curve, an aqueous solution of $\mathrm{Ca}\left(\mathrm{NO}_{3}\right)_{2}$ was injected into the sampling lance during $27 \mathrm{~min}$. The signal response, quantified by the calcium concentrations measured with the ICP-OES, is shown in Fig. 3. After $8.5 \mathrm{~min}$ the calcium signal started to rise in the ICP-OES measurements. After another 2 min it reached $90 \%$ of the maximum signal height. In contrast to this relatively fast response time (excluding dead time needed for the actual transport) the signal showed a strong tailing after the feed had been stopped. From the moment 


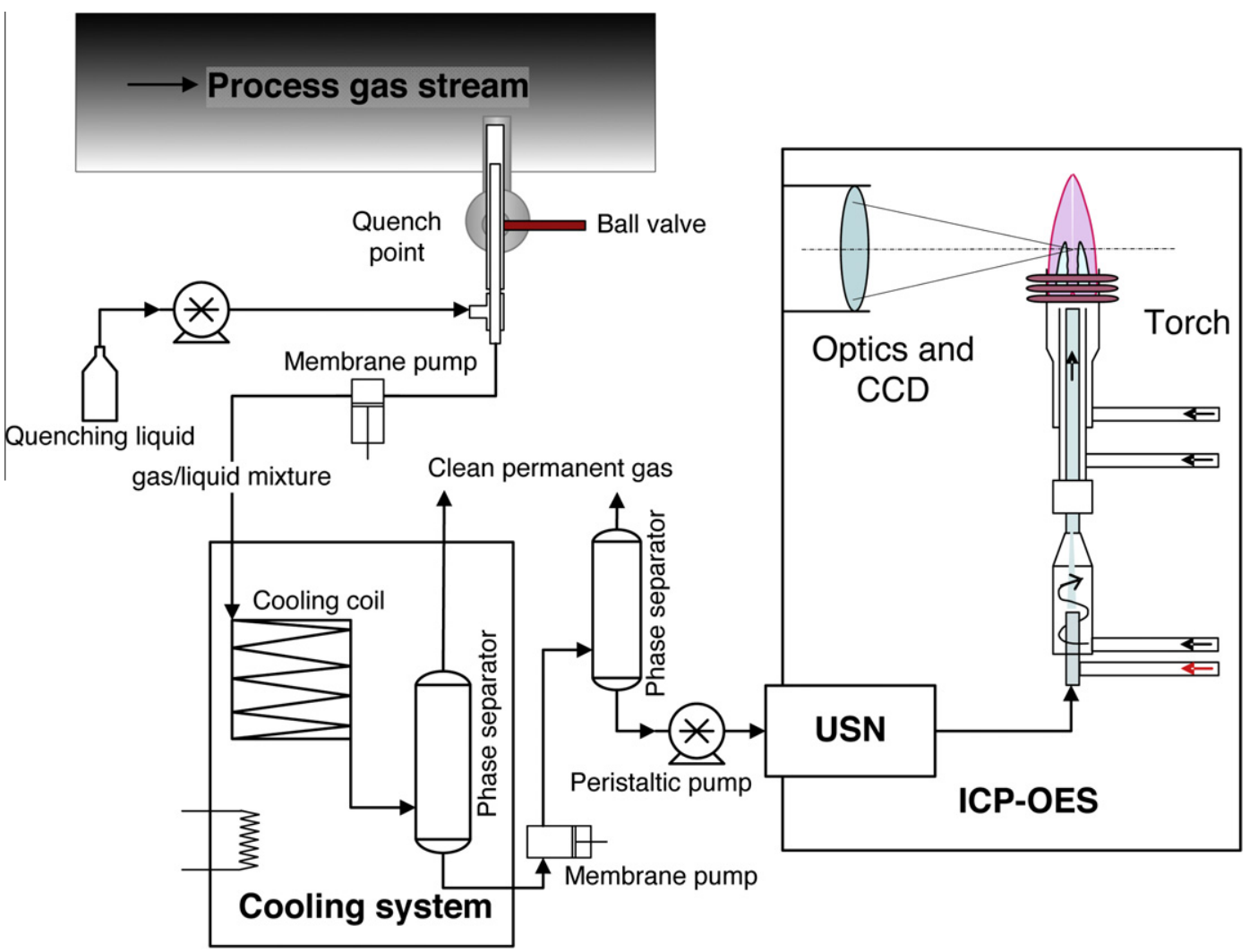

Fig. 2. Flowsheet of the liquid quench measurement setup for the ICP-OES.

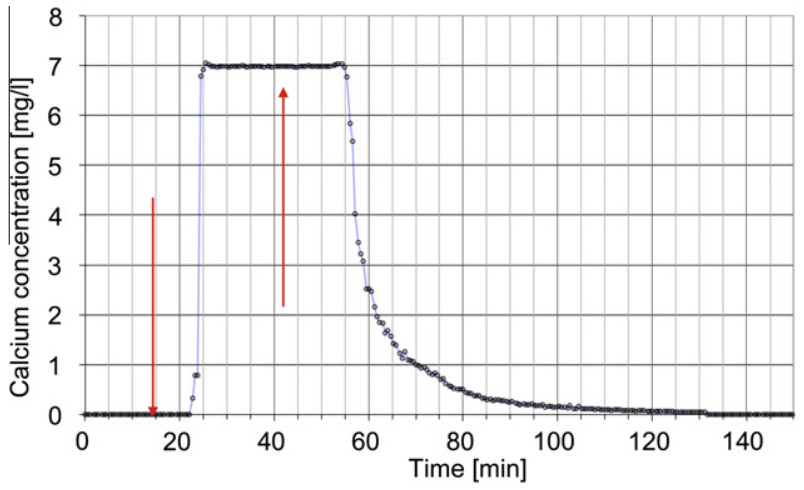

Fig. 3. Step response and fading curve of the sampling system coupled to the ICPOES; the arrows mark the start and stop of the feed of calcium nitrate solution at the sampling lance.

the calcium concentrations started to decline it took another 21.5 min for the signal to drop below $10 \%$ of the maximum signal height. Since the signal tailing is much shorter (about a factor five) when measuring gaseous samples, this response behavior is mostly due to the liquid sampling technique and its tendency for backmixing of solvent during transport. Backmixing is also the most likely source of discrepancy between the actual feed time of $27 \mathrm{~min}$ and the length of the signal plateau of $30 \mathrm{~min}$.

\subsection{Wood combustion facility}

The wood combustor where we carried out our field measurement campaign exclusively uses waste wood as a feedstock. The facility is using a fixed bed combustion that has an ascending conveyor to transport the feedstock onto the grate. The combustion was conducted at an air to fuel ratio of 1.57 leading to oxygen levels around $10 \%$ in the flue gas. The schematic of the combustor facility is shown in Fig. 4. The average residence time of the feedstock on the grate itself is $20 \mathrm{~min}$ to $25 \mathrm{~min}$ via a boiler the combustion heat is transferred to steam, which in turn drives a small turbine. The heat and power generation amounts to $1.6 \mathrm{MW}$, and 11.3 MW, respectively.

The sampling location is located just after the grate and boiler, therefore the gas can be considered to be in its raw state coming directly from the combustion. The process conditions at the sampling location are characterized by a temperature of $250-300^{\circ} \mathrm{C}$ and a pressure of 20 mbar below atmospheric pressure. The unfiltered sample was sucked into the sampling lance, quenched and continuously transported to the ICP-OES (see also Fig. 3).

The plant was equipped with a commercial gas measurement system, which provided concentrations of oxygen, nitrous oxides $\left(\mathrm{NO}_{X}\right.$, sum of nitrous monoxide and nitrous dioxide) and carbon monoxide. Additionally the processes heat output is supervised by metering the steam production at intervals of around $3 \mathrm{~min}$.

\subsection{Waste wood feedstocks}

The feedstock consisted of typical waste wood that is heterogeneous and strongly varies with regard to chemical composition, particle size (fragmented size and lumpiness) and foreign substances (Hasan et al., 2011; Williams, 2005), much like it has been reported for municipal solid waste by numerous sources (Van Der Sloot et al., 1997; Belevi and Moench, 2000; Morf et al., 2000; Poole et al., 2007). This variability stems from the different sources making up waste wood ranging from natural wood residues (e.g. pallets, wood shavings) to problematic wood wastes (e.g. doors, windows, facade planks). In this study we present data from the 


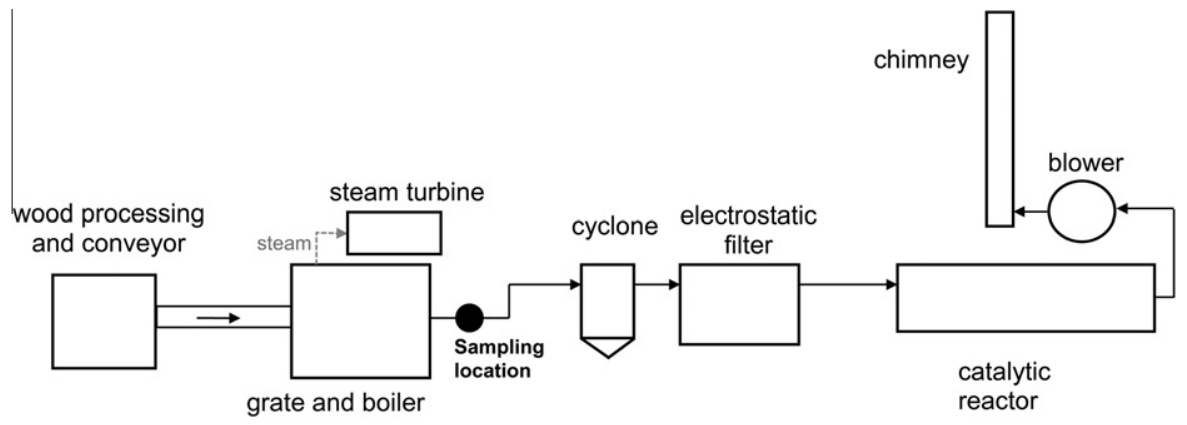

Fig. 4. Schematic of the combustor facility.

combustion of two waste wood feedstocks (W1 and W2) that mainly differ in their percentage of heavy metals (from adhesives or paint) and wood preservatives. To determine the elemental compositions of strongly heterogeneous waste streams such as waste wood requires extremely laborious procedures. In the literature it has therefore also been proposed to characterize feedstocks by their ashes (Belevi and Moench, 2000; Belevi and Langmeier, 2000; Morf et al., 2000).

\section{Results}

In the following section we present data from measurements taken with our mobile ICP-OES using the liquid quench method at a waste wood combustion facility in Switzerland. The time series represents a continuous measurement of raw combustion gas over a period of $3.3 \mathrm{~h}$ ( $200 \mathrm{~min})$. After the change of feedstock at $62 \mathrm{~min}$ a period with a mixed composition of the two feedstocks followed, during which the operators aimed to stabilize the bulk process conditions, i.e. to obtain a stable steam production. Table 2 presents a number of feedstock characteristics and operating parameters:

The difference in heating values is mainly influenced by the high water content of W1. The feed rate for both feedstocks was adjusted in order to generate approximately $13 \mathrm{t} / \mathrm{h}$ of steam. Since feedstock W1 showed markedly inferior combustibility, the feed rate was adjusted to a much higher value. Concurrently this also meant that the combustion efficiency for feedstock W1 was a third lower than for W2.

\subsection{Average elemental concentrations}

The time frames used to calculate the average concentrations for the two feedstocks W1 and W2 were from 0 min to $62 \mathrm{~min}$ and $122.4 \mathrm{~min}$ to $196.5 \mathrm{~min}$, respectively. In Fig. 5A the elemental concentrations in the two feedstocks are plotted against each other (as black data points). The measurements of elemental composition have been provided to us by the operators of the combustion facility but were carried out by a certified lab. Nonetheless considerable variations are to be expected from feedstock flow that is burned over the course of the measurements. The feedstock W2 contained a visibly (and also according to element concentration

Table 2

Comparison of waste wood feedstocks.

\begin{tabular}{lll}
\hline Characteristic & W1 & W2 \\
\hline Water content $(\%)$ & 30 & 12 \\
Lower heating value $(\mathrm{MJ} / \mathrm{kg})$ & 13.3 & 15.2 \\
Average steam production $(\mathrm{t} / \mathrm{h})$ & 13.2 & 13.1 \\
Feed rate $(\mathrm{t} / \mathrm{h})$ & 4.6 & 2.33 \\
Combustion efficiency $(\%)$ & 47.3 & 72.8 \\
\hline
\end{tabular}

of the input) larger share of feedstock heavily treated with wood preservatives. Incomplete values exist for carbon, hydrogen and nitrogen, where only a value for feedstock W2 was available. Addi-
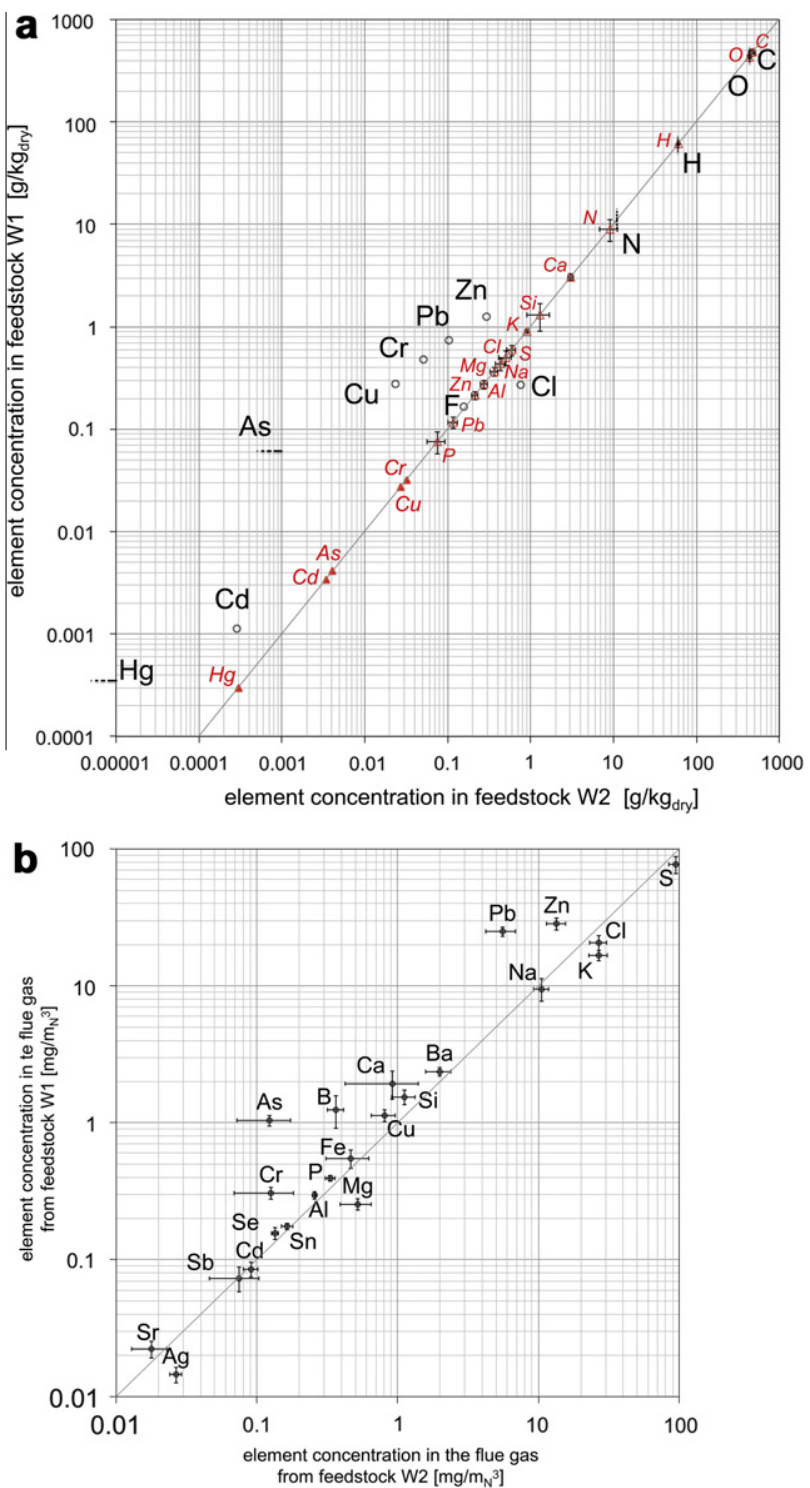

Fig. 5. (A) Element concentrations in the waste wood feedstocks; black circles: values from $\mathrm{W} 1$ and $\mathrm{W} 2-\mathrm{C}, \mathrm{H}$, and $\mathrm{N}$ : only values for $\mathrm{W} 2$ - As and $\mathrm{Hg}$ contents in W2 below the detection limit; red circles: literature values for waste wood - open circles with error bars: (Frandsen et al., 2007), closed circles: (von Scala, 1998); (B) Average element concentrations in the combustion flue gas from waste wood W1 and W2. (For interpretation of the references to color in this figure legend, the reader is referred to the web version of this article.) 

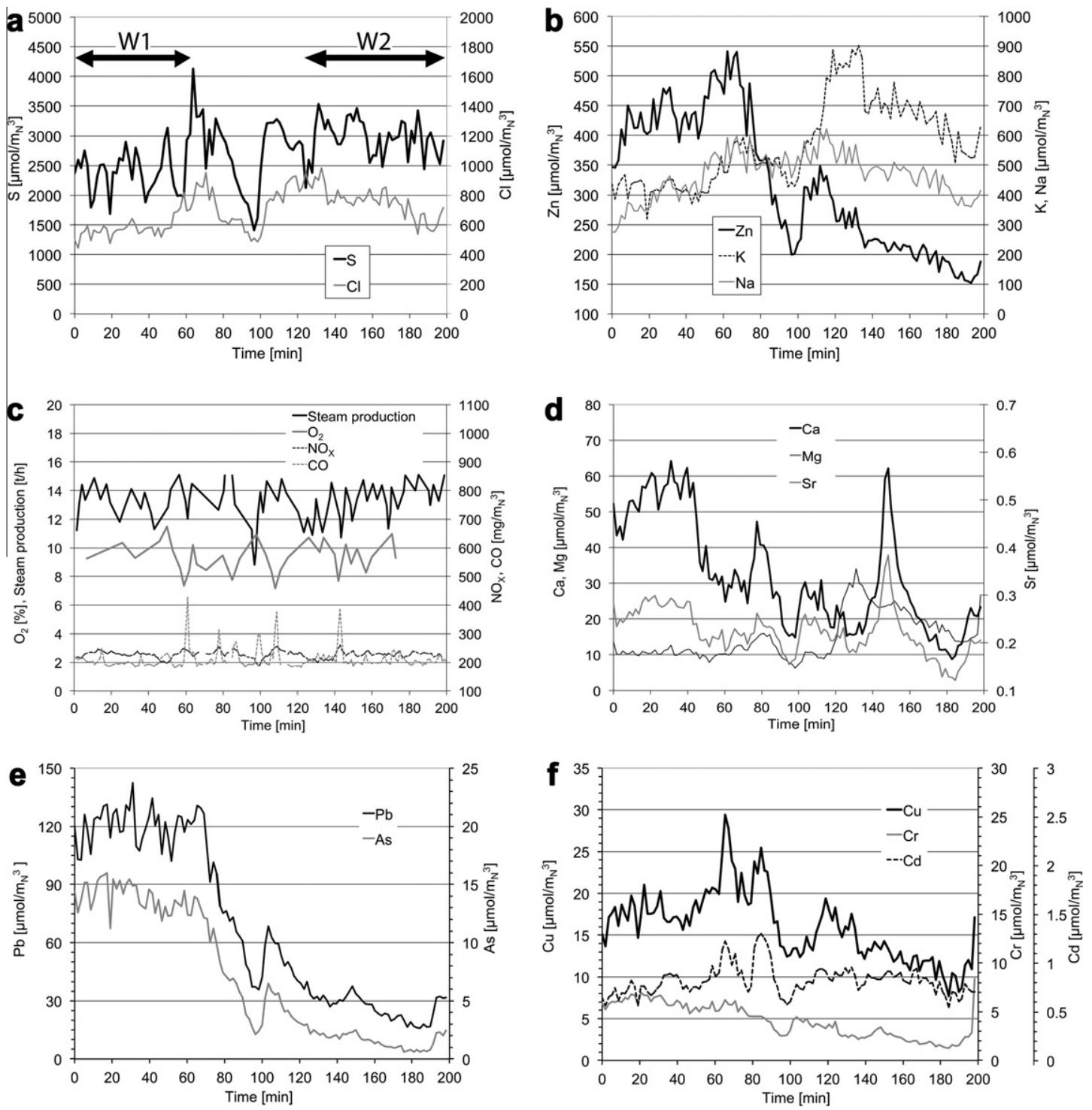

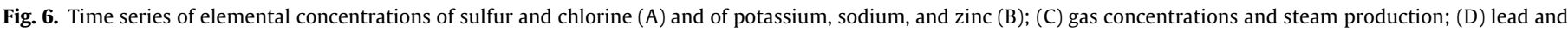
arsenic; (E) and copper, chromium, and cadmium; (F) calcium, magnesium, and strontium.

tionally for the elements mercury and arsenic the exact content for W1 is known, but for W2 only maximum values were determined as contents for both lay below the detection limit. Since for some elements of interest (e.g. sodium and potassium) the content in the feedstocks were not determined, Fig. 5A was complemented with data on element concentrations from literature (Frandsen et al., 2007; von Scala, 1998). The error bars shown for the literature values have been derived from at least five $(\mathrm{C}, \mathrm{H}, \mathrm{N})$ or ten (all other elements) analyses (Frandsen et al., 2007). The diagonal line in Fig. 5A represents all points of equal concentrations in the two waste wood feedstocks. The literature data consist of a single value per element and therefore all points lie on the diagonal line in the graph. In Fig. 5B the mean values of the elemental concentration in the flue gas from the combustion of the two waste wood feedstocks W1 and W2 are depicted. Most of the elements have a very similar concentration in flue gas from both feedstocks, to facilitate this comparison the diagonal $y$ equals $x$ has been added to the graph. For arsenic, lead, zinc, boron, chromium, and calcium significantly higher values are found in the flue gas from the combustion of the higher contaminated waste wood W1. In contrast, bulk elements that are main components of biomass and like sodium, potassium, magnesium, sulfur and chlorine gave lower concentrations during combustion of feedstock W1.

\subsection{Time series of elemental concentrations measured at the wood combustion facility}

The time series represents 116 single measurements of raw combustion gas that were continuously recorded in intervals of $103 \mathrm{~s}$ over the course measurement period of $200 \mathrm{~min}$. Fig. 6A shows sulfur and chlorine concentrations and Fig. 6B those of potassium, sodium and zinc. Together with lead these elements registered with the highest mass concentrations in the flue gas ranging from $4 \mathrm{mg} / \mathrm{m}_{\mathrm{N}}^{3}$ to over $100 \mathrm{mg} / \mathrm{m}_{\mathrm{N}}^{3}$. In Fig. $6 \mathrm{~A}$ the time frames used to calculate the average concentrations for the two feedstocks W1 (from 0 min to $62 \mathrm{~min}$ run time) and W2 (from $122.4 \mathrm{~min}$ to $196.5 \mathrm{~min}$ ) are marked with arrows. Both sulfur and chlorine showed a slightly lower concentration in the flue gas from feedstock W1. Similarly the potassium also increased after changing the feedstock, whereas the sodium concentration did not 
change significantly. In contrast to that the concentration of zinc strongly declines after the feedstock change from W1 to W2.

The chlorine and potassium concentrations have an almost identical pattern of fluctuations over time. Sodium and zinc also show very similar variations. Though, the molar concentration of zinc is higher than that of sodium in the flue gas from feedstock W1 but the opposite is true for the flue gas from feedstock W2. This indicates an additional zinc source in the case of feedstock $\mathrm{W} 1$, which is rather stable in its emission characteristic and therefore does not distort the correlation of the two elements.

In Fig. 6C the time series of the control parameters from the combustion facility are depicted. Immediately following the maximum recorded steam production of $15 \mathrm{t} / \mathrm{h}$ at $81 \mathrm{~min}$ the sensor logged two false zero data points because of signal overflow (visible in the graph as a gap). At 97 min the steam production falls down to a global minimum of $9 \mathrm{t} / \mathrm{h}$, a sharp decline is also visible in the element concentrations of sulfur, calcium, zinc, lead, and arsenic. After a transition period of almost $1 \mathrm{~h}$ the steam production becomes more stable again. The oxygen concentration is only logged in intervals of about $10 \mathrm{~min}$. Nevertheless, a counter movement to the fluctuations of the steam production can be observed. At run time $170 \mathrm{~min}$ there was a sensor outage and therefore no oxygen concentrations were logged for the rest of the measurement period. The carbon monoxide concentrations exhibit a plateau at approximately $200 \mu \mathrm{g} / \mathrm{m}_{\mathrm{N}}^{3}$ with several sharp peaks. The three highest peaks in excess of $300 \mu \mathrm{g} / \mathrm{m}_{\mathrm{N}}^{3}$ coincide with local oxygen minima (less than $8 \%$ oxygen) and steam production maxima. After run time $145 \mathrm{~min}$ no values above $250 \mu \mathrm{g} / \mathrm{m}_{\mathrm{N}}^{3}$ were registered. The $\mathrm{NO}_{X}$ concentration shows a low degree of variation compared to the oxygen or carbon monoxide concentrations. To a minor extent it shows similar trends as the carbon monoxide concentrations and follows the trend of the steam production. The average $\mathrm{NO}_{X}$ concentrations for the two feedstocks are nearly identical with $212 \mu \mathrm{g} / \mathrm{m}_{\mathrm{N}}^{3}$ (W1) and $204 \mu \mathrm{g} / \mathrm{m}_{\mathrm{N}}^{3}$ (W2). In contrast to this the standard deviations of 39.4 (W1) and 14.6 (W2) differ strongly and are indicative of more stable bulk conditions during the feed of W2.

Fig. 6D shows the concentrations of the earth alkali elements calcium, magnesium and strontium. The devolution of the magnesium concentration shows some similarity to the one of calcium. Though, the magnesium concentration rises after changing the feedstock. A much stronger similarity was detected between calcium and strontium curves. Free linear correlation resulted in the following equations (all units are in $\mu \mathrm{mol} / \mathrm{m}_{\mathrm{N}}^{3}$ ):

Strontium versus calcium (W1) $y=0.0029 x+0.1135$

$$
R^{2}=0.86964
$$

Strontium versus calcium (W2) $y=0.0045 x+0.1011$

$$
R^{2}=0.94321
$$

For feedstock W1 the absolute difference between the two concentrations is higher than for W2. Therefore there is a calcium source in W1 that does not contain strontium in a similar concentration as it is the case for W2. The differences in the slope of the cross-correlations for the two feedstocks points to a difference in the molar ratio of the two elements in the feedstock itself. Calcium and strontium are both abundant in the earth's crust. They may therefore stem from leftover soil material that was fed to the combustor along with the waste wood.

Lead and arsenic (Fig. 6E), copper, and chromium (Fig. 6F) all show a decrease after changing of the feedstock from W1 to W2. Screening of the element concentrations showed that lead and arsenic showed very similar emission patterns. A strong free linear correlation of the elemental concentration is observed not only for feedstock W2, but for the complete time series composed of 116 single measurements as well (all units are in $\mu \mathrm{mol} / \mathrm{m}_{\mathrm{N}}^{3}$ ):

Lead versus arsenic (W1) $y=4.0998 x+63.079 \quad R^{2}=0.30132$

Lead versus arsenic (W2) $y=9.3973 x+11.461 \quad R^{2}=0.92461$

Lead versus arsenic (all measurements) $\quad y=7.5841 x+15.918$

$R^{2}=0.97938$

The values of cadmium (Fig. 6F) are generally very low, but they show a strong variability with distinct peaks throughout their concentration time series, but no significant difference between the two feedstocks.

In Fig. 7 the molar concentrations of sodium, potassium and zinc were plotted against the concentration of chlorine. For the
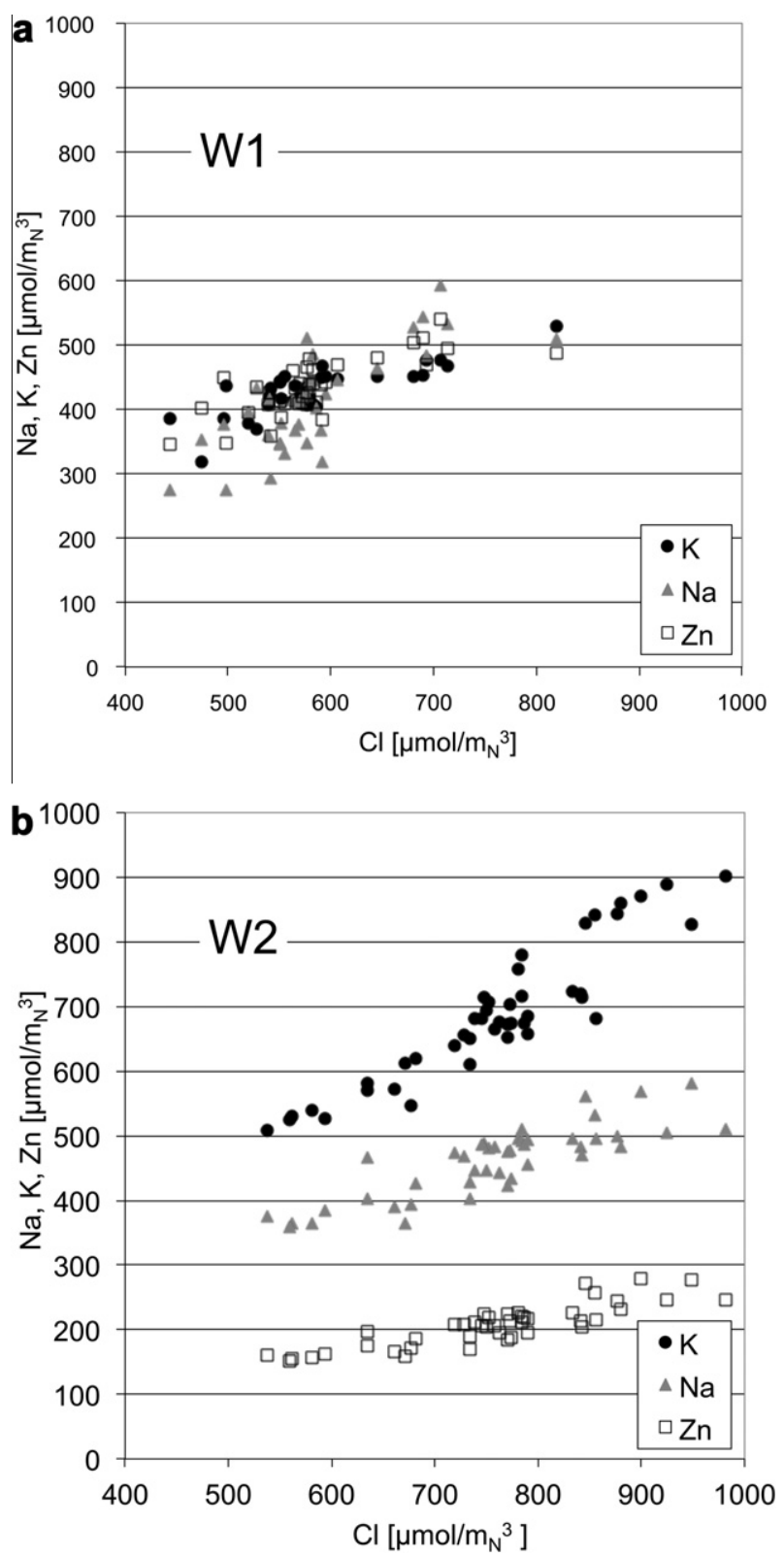

Fig. 7. Cross correlation of the molar concentrations of sodium, potassium and zinc versus the concentrations of chlorine; (A) values from the combustion of waste wood W1 (B) values from the combustion of waste wood W2. 
feedstock W1 there is slight trend (with considerable amount of variance) of increasing alkali and zinc concentration with rising chlorine concentration. Furthermore, during combustion of W1 the molar concentrations of sodium, potassium, and zinc are at similar levels. In contrast to this observation the concentrations of sodium, potassium, and zinc for feedstock W2 are at different levels. In addition, for feedstock W2 all of the plots show a high degree of free linear correlation with clear differences in intercept as well as slope (all units are in $\mu \mathrm{mol} / \mathrm{m}_{\mathrm{N}}^{3}$ ):

Chlorine versus sodium (W2) $y=0.4538 x+116.5$

$R^{2}=0.72016$

Chlorine versus potassium (W2) $\quad y=0.934 x-22.002$

$R^{2}=0.86111$

Chlorine versus zinc (W2) $y=0.2718 x+0.7086$

$R^{2}=0.75396$

\section{Discussion}

In this study a direct gas measurement technique as well as a liquid sampling technique has been investigated for their suitability to measure element concentrations in thermal process gases. To investigate the transport efficiency of direct gas measurements we used aerosols generated by the USN. Even when transported through a sampling line heated to $120^{\circ} \mathrm{C}$, we observed strong signal losses for distances greater than $3 \mathrm{~m}$. This suggests that condensation and sorption phenomena occur within the sampling line, which in turn degrade the detected signal intensities. Table 3 gives an overview of the advantages and disadvantages of the gas and liquid sampling methods used in this study.

In our field measurement campaign conducted with the liquid quench method, we observed 23 elements with signals at least threefold over the standard deviation of the blank signal covering a concentration range of almost four orders of magnitude.

To assess the efficiency of analyte transport we conducted a comparison of the measured signals with available literature data. To this end we compared the ratios between elemental concentrations and found a reasonable agreement with literature values (Lind et al., 1999; Krook et al., 2004; Pedersen et al., 2009).

Special cases regarding the transport efficiency include a number of sulfur compounds contained in the process gas, as these compounds tend to adsorb onto metal surfaces (Kim et al., 2006a). A further loss of analyte can also occur when transporting sulfur containing sample streams through silicone or PTFE tubes (Kim et al., 2006b; Sulyok et al., 2002; Kuster and Goldan, 1987). Beside signal loss in general, adsorption phenomena can lead to an increased signal tailing when concentration changes occur (slower ramp-up and decelerated signal decline). Though, considering the strong variability of sulfur concentrations over time (see Fig. 6A), it seems that the sorption phenomena have a less pronounced effect than the changing concentrations that stem from the process itself. One way of circumvent this limitation is the use of special surface coatings available such as sulfinert ${ }^{\circledR}$ that prevents sorption of sulfur. An additional difficulty with sulfur is the volatile character of some of the commonly occurring sulfur compounds. The volatility of theses sulfur compounds lead to an incomplete recovery via the quenching liquid since a significant portion can escape via the gas exhaust (see Fig. 1). For biomass gasification for example hydrogen sulfide is the dominant sulfur species (Johansson et al., 1999; Cui et al., 2010), where in biomass combustion sulfur dioxide is a commonly occurring compound.

The higher content (in feedstock and flue gas) of toxic elements in $\mathrm{W} 1$ reflects the higher fraction of preservatives in that waste wood feedstock. Among the most common wood preservatives are chromium-copper-arsenate, chromium-copper boron salts and copper-zinc-arsenate (Hasan et al., 2011). Additional sources of toxic elements can be paint and varnish (from windows and doors) containing lead and zinc compounds, e.g. white lead: $\left(\mathrm{PbCO}_{3}\right)_{2} x \mathrm{~Pb}(\mathrm{OH})_{2}$.

The measured concentrations in the flue gas from the two feedstocks are very similar for the bulk elements. This suggests that the employed sampling and detection method is highly reproducible. On the other hand the fact that we detected clear differences for heavy metals and arsenic concentrations suggests a high sensitivity of the employed method. It also indicates that there is no element specific loss stemming from the sampling's transport method.

From the times series of elemental concentrations some important conclusions can be drawn. Firstly, the concentrations of sodium and potassium during combustion of feedstock W2 seem to reflect the bulk conditions of the combustion quite well, as they show a similarity to the steam production. Secondly, the strong fluctuations even within one feedstock type demonstrate the heterogeneity of the feedstock composition, as has been reported before for combustion of municipal solid waste (Poole et al., 2007). Additionally, several strong cross correlations between the devolution of elemental concentrations have been found. The intercept of the free linear correlation could be interpreted as the amount of one element released independently of the other element's emissions. This occurs either because the feedstock has different source compounds present in independent concentrations or these compounds have a different transfer behavior. For cases located at a positive intercept, the element assigned to the $y$-axis has an additional source independent of the element assigned to the $x$ axis. The slope of the free linear correlation is influenced by the molar ratios of the elements in the source compounds as well as their tendency to transfer to the gas phase (as expressed by the transfer coefficient). To exclude artifacts stemming from strongly

Table 3

Comparison of liquid versus gas quench sampling.

\begin{tabular}{|c|c|c|}
\hline Characteristic & Liquid quench & Gas quench \\
\hline Cooling efficiency of the quench & Efficient cooling through high heat capacity of the liquid & Less efficient cooling \\
\hline $\begin{array}{l}\text { Dilution/concentration of the } \\
\text { sample gas }\end{array}$ & $\begin{array}{l}\text { Possibility to enrich the element in the sampling solution through } \\
\text { manipulation of gas to liquid ratio }\end{array}$ & Sample gets diluted by quench gas \\
\hline Necessity for heated equipment & No heated parts needed & $\begin{array}{l}\text { Heated pumps and valves are necessary to prevent } \\
\text { condensation }\end{array}$ \\
\hline Transport efficiency & No apparent signal loss even for sampling lines with lengths up to $32 \mathrm{~m}$ & $\begin{array}{l}\text { High signal loss for sampling lines of more than } \\
3 \mathrm{~m} \text { length }\end{array}$ \\
\hline Time delay & Long - approx. $1 \mathrm{~min} / \mathrm{m}$ & Short - approx. $1.5 \mathrm{~s} / \mathrm{m}$ \\
\hline $\begin{array}{l}\text { Robustness for changing gas } \\
\text { composition }\end{array}$ & High & Low (plasma flame can get extinguished) \\
\hline Spiking & Feasible for virtually any element & Restricted to volatile compounds \\
\hline
\end{tabular}


differing element concentrations between feedstock W1 W2, we checked if the correlations simply arose from a decay curve or a form of carry-over from the sampling system. A carry-over extending over the whole measurement period can be excluded since it would show up in the time series of all elements (see Fig. 6). The possibility of a decay curve generating the correlation can be excluded as well, since decay curves must be strictly monotonic decreasing, which was not observed. For example, in the case of lead and arsenic there is a strong peak visible at $105 \mathrm{~min}$ (see Fig. 6E). Furthermore, we also investigated for possible interference in elemental emission lines present in the ICP-OES signal. This was especially important when comparing element concentrations with large differences in their signal intensities and therefore also in their molar concentrations. We first compared the emission lines used for the calibration to one another and then in a second step checked for other emission lines in the spectral vicinity that usually exhibit a lower intensity.

Strong correlations in elemental concentrations were found among sodium, potassium and zinc against chlorine for feedstock W2. Others have reported similar findings (Poole et al., 2007; Khan et al., 2009; Jakob et al., 1996; Belevi and Langmeier, 2000; Struis et al., 2004). Under the given conditions of combustion below $1000{ }^{\circ} \mathrm{C}$ and chlorine contents of at least $0.3 \%$ in the feedstock, the dominant species of alkali emissions is expected to be potassium chloride (Khan et al., 2009; Monkhouse, 2002). Alkalis have been ascribed a carrier function for chlorine (Monkhouse, 2002), and chlorine in turn has a well-documented carrier function for the volatilization of metals (Khan et al., 2009; Struis et al., 2004; Belevi and Langmeier, 2000; Jakob et al., 1996). Two mechanisms involving chlorine can lead to a concurrent mobilization of alkalis and metals. Firstly, gaseous chlorine compounds mobilize alkalis and metals simultaneously and secondly metals can be mobilized through alkali chlorides directly (Jakob et al., 1996). Therefore detection of alkalis in flue gases has a potential to be used as a proxy variable for heavy metal emissions. In this context inexpensive online methods like surface ionization (Wellinger et al., 2011) that enable a monitoring of alkali emissions could be of value.

In case sulfur is present in high enough amounts to compete with chlorine for reactions with zinc, volatilization of zinc can be inhibited (Struis et al., 2004). The fact that the concentrations of zinc, sodium and potassium versus the concentrations of chlorine were more tightly correlated in $\mathrm{W} 2$ as compared to $\mathrm{W} 1$, provides further evidence that in W1 the combustion efficiency was uneven and possibly more restricted to the surface layers of the feedstock particles. This also leads to an overrepresentation of elements in the flue gas that stem from surface applied wood preservatives compared to elements that represent the bulk composition of W1.

Since arsenic has, in contrast to lead, a rather limited volatility under oxidative conditions, these two elements have strongly differing behaviors and therefore are not expected to show a correlated emission behavior. Both the high lead and arsenic levels in W1 probably stem from surface treatment of the wood (Pedersen et al., 2009) and therefore a correlation in the devolution of their concentrations could largely be due to entrainment.

\section{Conclusions}

In Section 2.2.1 we demonstrated that calibrating with liquid standards and a nebulizer is a precise and reliable method for calibrating element signals from direct injection of sample gas. Depending on the composition of the process gas (tars, particles), an additional way to calibrate would greatly improve the overall accuracy of the method (see last paragraph). For sampling lines having lengths of more than $3 \mathrm{~m}$, liquid sampling provided superior signal intensity.
The following conclusions can be drawn from the results of our field measurements:

1. With the current sampling setup it is possible to measure concentrations of trace elements even in the sub-ppm $(\mathrm{m} / \mathrm{V})$ range (down to values of $0.01 \mathrm{mg} / \mathrm{m}_{\mathrm{N}}^{3}$ ).

2. The liquid quench system employed for the described measurement campaign enabled us to take continuous measurements at intervals of $1.7 \mathrm{~min}$ over a period of up to $7 \mathrm{~h}$ without any apparent condensation or blockage problems.

3. W1 versus $W 2$ yielded almost identical element concentrations of bulk elements in the flue gas. This speaks to a high reproducibility of the measurement method coupled with the sensitivity to resolve differences stemming from the feedstock composition.

With a number of field measurement problems solved (analyte transport efficiency, tar and soot content) this method becomes suitable for characterizing element emissions for a broad range of thermal processes including difficult sampling situations involving high tar and particle loads. For example we were able to demonstrate that the ICP-OES is sensitive enough to verify elemental concentrations specified as upper limits for gas turbines (except for vanadium) (GeneralElectric, 2007).

There is potential for further improvement. The use of a direct injection nebulizer is expected to increase nebulizing efficiency more than twofold to over $20 \%$. Furthermore adding a spike of known concentration to the solvent used for the liquid quench would allow for the application of the standard addition method. Gas quench spikes could also be employed though they are inherently restricted to volatile metals. Additional improvements could be realized by optimizing the calibrations for each element according to its expected concentration range. This would mean that the concentrations of the standards are adjusted to the lowest possible range, without creating a need for extrapolation to calculate the concentrations of the samples. Compared to a standard calibration that ranges over two orders of magnitude or more, the detection limit can be improved by at least one order of magnitude by using lower concentrated standards and a narrower calibration range.

\section{Acknowledgments}

We thank Albert Schuler for his technical support, which enabled us to conduct our field measurements. Further we thank Jörg Schneebeli for valuable discussions and technical support during the development of the dilution system and sampling lance. Financial support was obtained from swisselectric research (Project TREPGAS) and the Swiss Federal Office of Energy (Project 102093). Both of the aforementioned projects were imbedded in the framework of the Competence Center Energy and Mobility (CCEM) Project "Woodgas-SOFC".

\section{References}

Belevi, H., Langmeier, M., 2000. Factors determining the element behavior in municipal solid waste incinerators. 2. Laboratory experiments. Environmental Science and Technology 34 (12), 2507-2512.

Belevi, H., Moench, H., 2000. Factors determining the element behavior in municipal solid waste incinerators. 1. Field studies. Environmental Science and Technology 34 (12), 2501-2506.

Clarkson, P.J., Poole, D.J., Ryu, C.K., Sharifi, V.N., Swithenbank, J., Waarlo, H.J., Ardelt, D., Falk, H., 2003. Continuous measurement of metals in flue gas using ICP-OES. Analytical and Bioanalytical Chemistry 377 (1), 39-47.

Cui, H., Turn, S.Q., Keffer, V., Evans, D., Tran, T., Foley, M., 2010. Contaminant estimates and removal in product gas from biomass steam gasification. Energy and Fuels 24 (2), 1222-1233.

Demirbas, A., 2005. Potential applications of renewable energy sources, biomass combustion problems in boiler power systems and combustion related environmental issues. Progress in Energy and Combustion Science 31 (2), 171-192. 
Frandsen, F.J., van Lith, S.C., Korbee, R., Yrjas, R., Backman, P., Obernberger, I., Brunner, T., Joeller, M., 2007. Quantification of the release of inorganic elements from biofuels. Fuel Processing Technology 88 (11-12), 1118-1128.

GeneralElectric, 2007. Specifications for Fuel Gases for Combustion in Heavy-Duty Gas Turbines (GEI 41040j)

Hasan, A.R., Schindler, J., Solo-Gabriele, H.M., Townsend, T.G., 2011. Online sorting of recovered wood waste by automated XRF-technology. Part I: detection of preservative-treated wood waste. Waste Management 31 (4), 688-694.

Jakob, A., Stucki, S., Struis, R.P.W.J., 1996. Complete heavy metal removal from fly ash by heat treatment: influence of chlorides an evaporation rates. Environmental Science and Technology 30 (11), 3275-3283.

Johansson, E.M., Berg, M., Kjellstrom, J., Jaras, S.G., 1999. Catalytic combustion of gasified biomass: poisoning by sulphur in the feed. Applied Catalysis B Environmental 20 (4), 319-332.

Judex, J.W., 2010. Grass for Power Generation. Extending the Fuel Flexibility for IGCC Power Plants. PhD Thesis, ETH Zürich.

Khan, A.A., de Jong, W., Jansens, P.J., Spliethoff, H., 2009. Biomass combustion in fluidized bed boilers: potential problems and remedies. Fuel Processing Technology 90 (1), 21-50.

Kim, K.H., Choi, G.H., Choi, Y.J., Song, H.N., Yang, H.S., Oh, J.M., 2006a. The effects of sampling materials selection in the collection of reduced sulfur compounds in air. Talanta 68 (5), 1713-1719.

Kim, K.H., Ahn, J.W., Choi, Y.J., Nguyen, H.T., 2006b. The loss patterns of reduced sulfur compounds in contact with different tubing materials. Journal of Chromatography A 1132 (1-2), 228-233.

Kowalski, T., Judex, J., Schildhauer, T.J., Ludwig, C., 2011. Transmission of alkali aerosols through sampling systems. Chemical Engineering and Technology 34 (1), 42-48.

Krook, J., Martensson, A., Eklund, M., 2004. Metal contamination in recovered waste wood used as energy source in Sweden. Resources Conservation and Recycling 41 (1), 1-14.

Kuster, W.C., Goldan, P.D., 1987. Quantitation of the losses of gaseous sulfurcompounds to enclosure walls. Environmental Science and Technology 21 (8), $810-815$.

Lind, T., Valmari, T., Kauppinen, E.I., Sfiris, G., Nilsson, K., Maenhaut, W., 1999. Volatilization of the heavy metals during circulating fluidized bed combustion of forest residue. Environmental Science and Technology 33 (3), 496-502.

Ludwig, C., Lutz, H., Wochele, J., Stucki, S., 2001. Studying the evaporation behavior of heavy metals by thermo-desorption spectrometry. Fresenius Journal of Analytical Chemistry 371 (8), 1057-1062.

Ludwig, C., Wochele, J., Jorimann, U., 2007. Measuring evaporation rates of metal compounds from solid samples. Analytical Chemistry 79 (7), 2992-2996.
Monkhouse, P., 2002. Online diagnostic methods for metal species in industrial process gas. Progress in Energy and Combustion Science 28 (4), 331-381.

Monkhouse, P., 2011. On-line spectroscopic and spectrometric methods for the determination of metal species in industrial processes. Progress in Energy and Combustion Science 37 (2), 125-171.

Morf, L.S., Brunner, P.H., Spaun, S., 2000. Effect of operating conditions and input variations on the partitioning of metals in a municipal solid waste incinerator Waste Management and Research 18 (1), 4-15.

Nagel, F.P., 2008. Electricity from Wood through the Combination of Gasification and Solid Oxide Fuel Cells. PhD Thesis, ETH Zürich.

Pedersen, A.J., Frandsen, F.J., Riber, C., Astrup, T., Thomsen, S.N., Lundtorp, K., Mortensen, L.F., 2009. A full-scale study on the partitioning of trace elements in municipal solid waste incineration-effects of firing different waste types. Energy and Fuels 23 (7), 3475-3489.

Poole, D., Sharifi, V., Swithenbank, J., Ardelt, D., 2005. Identification of meta concentration fluctuations in waste-to-energy plant flue gases - a novel application for ICP-OES. Journal of Analytical Atomic Spectrometry 20 (9) 932-938.

Poole, D., Sharifi, V., Swithenbank, J., Argent, B., Ardelt, D., 2007. On-line detection of metal pollutant spikes in MSW incinerator flue gases prior to clean-up. Waste Management 27 (4), 519-532.

Struis, R.P.W.J., Ludwig, C., Lutz, H., Scheidegger, A.M., 2004. Speciation of zinc in municipal solid waste incineration fly ash after heat treatment: an X-ray absorption spectroscopy study. Environmental Science and Technology 38 (13) 3760-3767.

Sulyok, M., Haberhauer-Troyer, C., Rosenberg, E., 2002. Observation of sorptive losses of volatile sulfur compounds during natural gas sampling. Journal of Chromatography A 946 (1-2), 301-305.

Timmermans, E.A.H., de Groote, F.P.J., Jonkers, J., Gamero, A., Sola, A., van der Mullen, J.J.A.M., 2003. Atomic emission spectroscopy for the on-line monitoring of incineration processes. Spectrochimica Acta Part B - Atomic, Spectroscopy, 58(5):PII S0584-8547(03)00017-X.

Van Der Sloot, H., Vehlow, J., Eighmy, T.T., Hartlen, J., Hjelmar, O., Kosson, D., Sawell, S., 1997. Municipal Solid Waste Incinerator Residues. Elsevier Science, Amsterdam.

von Scala, C., 1998. The Influence of Contaminants on the Gasification of Waste Wood. PhD Thesis, ETH-Zürich.

Wellinger, M., Wochele, J., Biollaz, S., Ludwig, C., 2011. Sampling and online analysis of alkalis in thermal process gases with a novel surface ionization detector Energy and Fuels 25(9), 4163-4171.

Williams, P.T., 2005. Waste Treatment and Disposal, second ed. John Wiley \& Sons, Ltc. 